This item was submitted to Loughborough's Research Repository by the author.

Items in Figshare are protected by copyright, with all rights reserved, unless otherwise indicated.

\title{
Laser surface modification of carbon fiber reinforced composites
}

PLEASE CITE THE PUBLISHED VERSION

http://dx.doi.org/10.1080/10426914.2015.1019097

\section{PUBLISHER}

(c) Taylor and Francis

\section{VERSION}

AM (Accepted Manuscript)

\section{PUBLISHER STATEMENT}

This work is made available according to the conditions of the Creative Commons Attribution-NonCommercialNoDerivatives 4.0 International (CC BY-NC-ND 4.0) licence. Full details of this licence are available at: https://creativecommons.org/licenses/by-nc-nd/4.0/

\section{LICENCE}

CC BY-NC-ND 4.0

\section{REPOSITORY RECORD}

Nattapat, M., Sundar Marimuthu, A.M. Kamara, and Mohammadreza Nekouie Esfahani. 2019. "Laser Surface Modification of Carbon Fiber Reinforced Composites". figshare. https://hdl.handle.net/2134/19619. 
This article was downloaded by: [Loughborough University]

On: 19 June 2015, At: 01:33

Publisher: Taylor \& Francis

Informa Ltd Registered in England and Wales Registered Number: 1072954 Registered office: Mortimer House, 37-41 Mortimer Street, London W1T 3J H, UK

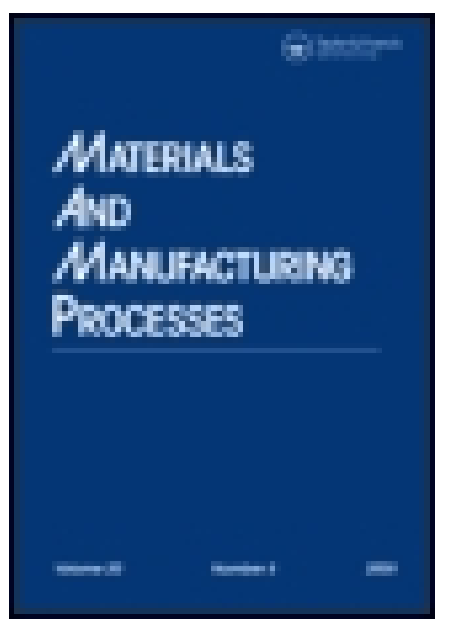

\title{
Materials and Manufacturing Processes
}

Publication details, including instructions for authors and subscription information:

http:// www. tandfonline.com/loi/Immp20

\section{Laser Surface Modification of Carbon Fibre Reinforced Composites}

\author{
M. Putt ${ }^{a}$, S. Marimuthu ${ }^{a}$, A. M. Kamara ${ }^{b} \&$ M. R. Nekouie Esfahani ${ }^{a}$ \\ a Optical Engineering Group, Wolfson School of Mechanical and Manufacturing, \\ Loughborough University, Loughborough, LE11 3TU, United Kingdom \\ ${ }^{\mathrm{b}}$ Department of Mechanical and Maintenance Engineering, Fourah Bay College, University of \\ Sierra Leone, Freetown, Sierra Leone \\ Accepted author version posted online: 01 Apr 2015.
}

\section{CrossMark}

Click for updates

To cite this article: M. Putt, S. Marimuthu, A. M. Kamara \& M. R. Nekouie Esfahani (2015): Laser Surface Modification of Carbon Fibre Reinforced Composites, Materials and Manufacturing Processes, DOI: 10.1080/ 10426914. 2015.1019097

To link to this article: http:// dx. doi.org/10.1080/10426914.2015.1019097

Disclaimer: This is a version of an unedited manuscript that has been accepted for publication. As a service to authors and researchers we are providing this version of the accepted manuscript (AM). Copyediting, typesetting, and review of the resulting proof will be undertaken on this manuscript before final publication of the Version of Record (VoR). During production and pre-press, errors may be discovered which could affect the content, and all legal disclaimers that apply to the journal relate to this version also.

\section{PLEASE SCROLL DOWN FOR ARTICLE}

Taylor \& Francis makes every effort to ensure the accuracy of all the information (the "Content") contained in the publications on our platform. However, Taylor \& Francis, our agents, and our licensors make no representations or warranties whatsoever as to the accuracy, completeness, or suitability for any purpose of the Content. Any opinions and views expressed in this publication are the opinions and views of the authors, and are not the views of or endorsed by Taylor \& Francis. The accuracy of the Content should not be relied upon and should be independently verified with primary sources of information. Taylor and Francis shall not be liable for any losses, actions, claims, proceedings, demands, costs, expenses, damages, and other liabilities whatsoever or howsoever caused arising directly or indirectly in connection with, in relation to or arising out of the use of the Content.

This article may be used for research, teaching, and private study purposes. Any substantial or systematic reproduction, redistribution, reselling, loan, sub-licensing, systematic supply, or distribution in any form to anyone is expressly forbidden. Terms \& Conditions of access and use can be found at http:// www.tandfonline.com/page/terms-and-conditions 


\title{
Laser Surface Modification of Carbon Fibre Reinforced Composites
}

\author{
M. Putt ${ }^{1}$, S. Marimuthu ${ }^{1}$, A. M. Kamara ${ }^{2}$, M. R. Nekouie Esfahani ${ }^{1}$ \\ ${ }^{1}$ Optical Engineering Group, Wolfson School of Mechanical and Manufacturing, \\ Loughborough University, Loughborough, LE11 3TU, United Kingdom, ${ }^{2}$ Department of \\ Mechanical and Maintenance Engineering, Fourah Bay College, University of Sierra \\ Leone, Freetown, Sierra Leone \\ Corresponding author: Dr. S. Marimuthu, Wolfson School of Mechanical and \\ Manufacturing Engineering, Loughborough University, UK. E-mail: \\ S.Marimuthu@lboro.ac.uk
}

\begin{abstract}
The removal of top resin layer is an essential task prior to adhesive bonding of carbon fibre reinforced polymer composites. This paper investigates the technical feasibility of using a low power continuous wave carbon dioxide laser for removing the top resin layer of CFRP without damaging the underlying fibre. The operating window and damaging threshold were experimentally determined. Irradiating the CFRP surface at a power of $14 \mathrm{~W}$, scanning speed of $880 \mathrm{~mm} / \mathrm{sec}$, and a beam overlap of $25 \%$ provides an optimal thermal condition for removal of top resin layer. A finite element model was used to explain the removal mechanisms.
\end{abstract}

KEYWORDS: cleaning, CFRP, laser, resin, surface, CO2, processing, manufacturing

\section{INTRODUCTION}

To date, there has been an exponential increase in demand for lightweight components for enhanced performance and realisation of economic and ecological gains. In that 
regard, owing to its unique characteristics, carbon fibre reinforced polymer (CFRP) are gaining industrial attention as their outstanding mechanical properties stand to satisfy market demand in a wide spectrum of industrial applications ranging from the fabrication of aircraft components and structures in the aerospace industry to prosthetics of artificial limbs in the medical sector [1-3]. This escalating trend in consumption and exploitation of CFRPs is forecasted to continually grow throughout the next decade with an annual growth rate of $16 \%$, reaching an estimated market value of $£ 4.4$ billion by 2017 [2].

However, despite the rising demand for CFRPs in many industrial applications, the joining technology of CFRP composite is yet among the primary challenges and concerns in its utilisation [4]. Conventional joining processes, which involve mechanical fasteners, can cause large stress concentrations as well as having significant effect on the lightweight potential of a part. In comparison, adhesion bonding shows excellent mechanical performance with a higher degree of material utilization. The joining mechanism involved in this method is primarily of a laminar substance-to-substance bond, which fundamentally improves and facilitates the joining capability and integrity of the constituent parts. Astrom [5] documented a comprehensive comparison between the two modes of composite joining processes and reported significant advantages in using adhesively bonded joints.

In order to achieve a strong and resistant adhesive bond, a suitable degree of adhesion must exist between the adhesive and the joining substrate. However, in reality, this is often affected and hindered by various forms of surface characteristics, such as excessive 
resin layer and residues of mould release agents [6]; and studies have presented the advantages of removing the top resin layer prior to adhesive bonding [7]. For this reason, a surface modification and treatment process is necessary prior to adhesive bonding in order to deliver a productively clean, preferably active and slightly rough surface. Stateof-the-art techniques in achieving this surface condition are either through chemical treatment or mechanical treatment, such as manual grinding or grit blasting $[4,8]$. However, these processes have several disadvantages with regard to process speed, complexity or the necessity of subsequent cleaning processes. Additionally, due to the extensive variation and parametric inconsistencies that are inherent in these surface preparation techniques, applying them for composite laminate structures such as CFRPs will not be an ideal and effective method [7].

Laser surface processing of CFRP laminates has shown and properly reported to be a promising technique to clean composite surfaces as well as deliver surface-to-surface cohesion that is both strong and reliable. Burnett [9] investigated the response and effects of surface treatment of indirect composites with Er:YAG and reported an increased bond strength primarily due to the loss of resin matrix and exposure of filler particles. This result was further supported and endorsed by Marcus [10] through a series of laser scans performed on CFRP composite panels using a frequency tripled Nd:YAG laser. Similar results were also obtained by Ozel [11] from surface treatment with Nd:YAG laser at a wavelength of $1064 \mathrm{~nm}$, which facilitated an improvement in the bonding strength of CFRP laminates by $39 \%$. Also worth noting is the contribution of Prinsloo [12], who 
demonstrated a TEA $\mathrm{CO}_{2}$ laser based coating removal system for metallic and composite aircraft panels.

From the increasing volume of research activities that has taken place in the field of laser surface processing of CFPR, it needs to be mentioned at this point that most of them involved the use of short pulsed ( nanosecond) lasers for the simple advantage of their small interaction time and that of the fact that most short pulsed laser processing of CFRP (with visible or infrared wavelength) are predominantly thermal dependent processes [8, 13]. However, the shortfall of short pulsed laser is with its disproportionally higher cost of ownership, which appeared to have been given little or no concern in its utilisation in previous research. Notwithstanding this, the comparatively lower capital and operating costs of low power continuous wave $(\mathrm{CW})$ carbon dioxide $\left(\mathrm{CO}_{2}\right)$ laser system portrays it as a highly cost-effective alternative for composite surface processing. What however needs to be taken into consideration is the fact that the most common CFRP surface processing requires the removal of top resin layer without damaging the fibre [7]. In order to determine the ideal condition and parameters for $\mathrm{CW} \mathrm{CO}_{2}$ laser surface modification process, it is important that the ablation and damage threshold of the CFRP resin and the fibre are identified since a large differential damage threshold (Decomposition Temperature) of these materials onto which the process relies is sure to result in effective removal of the top resin layer without damage being induced onto the underlying surface or fibre. 
With the details presented in Table 1[14], the possibility of this is speculated as the resin and composites are seen to have distinctively different thermo-optical properties and on the basis of which a $\mathrm{CW} \mathrm{CO}_{2}$ laser has the potential to provide and maintain the energy density level between the damage threshold of resin and composites; an approach which has proved successful in laser cleaning of metals [15]. The aim of this work is to therefore investigate the removal of top resin and contaminants layer from cross ply CFRP composites using a $\mathrm{CW} \mathrm{CO}_{2}$ laser and to study the mechanism governing the removal process. The effects of various process parameters were studied and the key process variables and their settings for the removal were established, thus facilitating the efficient processing of composites such as CFRPs at relatively low cost.

\section{MATERIALS AND METHODS}

The experimental setup was explicitly designed to determine the ideal processing conditions and parameters for the removal of top resin layer from CFRP surfaces without damaging the fibre or resin below the fibre. The optical arrangement within the $60 \mathrm{~W}$ Synrad $\mathrm{CO}_{2}$ marker laser system consists of a high speed galvanometer mirror to enable directional control of the beam across a two-dimensional plane. The testing samples were aerospace grade cross ply CFRP composite sheets of $3 \mathrm{~mm}$ thickness and cut to dimensions of $50 \times 50 \mathrm{~mm}$. These were irradiated in a horizontal position with the vertical beam incident at room temperature under atmospheric condition. The CFRP composite was held stationary on an open frame fixture throughout the scanning operation. 
In order to obtain the best resin ablation parameters, the experiment was executed in two phases as depicted in Figure 1. The first of these phases, which is schematically shown in Figure 1(a) made use of a linear line scanning technique to identify those process parameters and their range of values that would achieve suitable surface condition, where only a small proportion of the resin matrix is removed without damaging the underlying carbon fibers. Another important objective of this phase of the experiment was to determine the damage threshold of the epoxy resin and the fibre.

The identified parameters in this phase of the experiment were the laser scanning speed and power; and in the conduct of the experiment, the investigated sets of varying values for these parameters were as detailed in Table 2, while both the laser beam diameter and focal height were kept constant across all experiments at $0.3 \mathrm{~mm}$ and $200 \mathrm{~mm}$, respectively.

The scanning operation was such that linear beam scans were performed on the CFRP in distinct batches using the widest range of processing parameters available in the $\mathrm{CO}_{2}$ laser system. The laser scan for each set of values of the process parameters was examined under an optical microscope to determine that which delivered the most optimal surface condition without damaging and exposing too much of the underlying fibres.

The conduct of the second phase of the experiment made use of the values established in first phase as being suitable to deliver surface condition without damaging and exposing too much of the underlying fibres. This phase, as depicted in Figure 1(b) involved laser 
surface processing over a predetermined area on the CFRP surface and considered to deliver a more representative and realistic approach to laser surface modification in industrial application. The surface conditions of the CFRP samples were analysed through a NIKON optical microscope fitted with Image-Pro Premier 9.1 software. Furthermore, contact angle test was performed to assess the surface condition and adhesive behaviour of the irradiated surfaces. Lap-shear adhesive test was used to verify the effectiveness of using a $\mathrm{WC} \mathrm{CO}_{2}$ laser system as a surface processing technique prior to adhesive bonding.

\section{RESULTS AND DISCUSSION}

The results of the optical microscopic examination on the laser irradiated CFRP surfaces as obtained for the investigated sets of values of process parameters in Table 2 are as plotted as in Figure 2, on which three distinct zones marked A, B and C were observed, with their respective effects on CFRP surface condition being as indicated. Zone A represented the situation of a decrease in power with increase in speed and the effect was seen to be no fibre exposure and no resin removal. Zone B shows that at some optimal range of power and speed, complete removal of top resin was observed without any damage to the substrate material. Zone $\mathrm{C}$ represents the situation of increase in laser power and decrease in speed and as expected, this resulted in more ablation of resin and eventual damage of fibre at high laser power. 
A confirmation of these zonal effects is observed from the optical micrographs presented in Figure 3, which illustrate specifically the CFRP surface condition resulting from laser processing at a speed of $880 \mathrm{~mm} / \mathrm{sec}$ and laser powers of $8 \mathrm{~W}, 14 \mathrm{~W}$ and $20 \mathrm{~W}$ respectively.

A FEM based numerical analysis, as discussed by Negarestani [14], was used to further analyse and understand the mechanism of laser removal of top resin layer. The FEM model used in this work is based on heat conduction formulation. A single linear line laser processing of CFRP was modelled to analysis the effect of laser power on resin layer removal mechanism. The material properties used for the analysis were adopted form Negarestani [14]. The laser power was applied as a surface heat flux and the scanning speed was adjusted by controlling the interaction time. During the computation, any element with a temperature higher than the decomposition temperature of the fibre or resin was considered to be ablated. Convective and radiative heat loss was assumed on all the surfaces.

Figure 4 shows typical temperature and ablation characteristics obtained from the FEM simulation for the range of laser powers studied and specifically depicting the results for the power values of $8 \mathrm{~W}, 14 \mathrm{~W}$ and $20 \mathrm{~W}$ respectively. The results as can be evident in Figure 4(a) show no damage of fibres for Power $\leq 8 \mathrm{~W}$. For $8 \mathrm{~W}<$ Power $<20 \mathrm{~W}$, varying levels of removal of resin without damage to the substrate resulted and as shown in Figure 4(b) the best effect was observed with a power of $14 \mathrm{~W}$. As can be seen in Figure 4(c), laser power higher than $20 \mathrm{~W}$ resulted in damage of resin. These observations in ablation characteristics appears to have a direct relation to the maximum temperature 
observed in the irradiation zone thus portraying the usefulness of the FEM model as a feasible tool to predict an optimal temperature range that will be suitable for removal of top resin layer without damage to the substrate using a $\mathrm{CW} \mathrm{CO}_{2}$ laser beam.

In conducting surface modification over an area, the laser condition and parameters identified from the results of line scanning experiment were used as a reference. Shown in Figure 5 is the scheme used for laser surface modification over an area, which was carried out by alternating direction line scans and tests were undertaken for various beam overlaps. The laser beam overlap (\%) was calculated using the relation:

Laser beam overlap $\%=\frac{\text { Laser Beam Size }- \text { Offset Distance }}{\text { Laser Beam Size }} \times 100$

The experimental design, which detailed the values of the parameters for the laser surface modification over an area are as presented in Table 3. The laser power and speed were selected to achieve high speed with optimal surface modification performances. Various beam overlaps of $0 \%, 25 \%$ and $50 \%$ were investigated to find out the effect of beam overlap on the removal of resin layer. The laser treated area was examined using an optical microscope to access the surface conditions.

Figure 6 shows the surface condition of the CFRP surface irradiated for the laser beam overlaps investigated. Seen in the figure is that substrate damage increases with increase in laser beam overlap; an effect which could be attributed to the increase in heat input with increase in beam overlap. However, a beam overlap of $25 \%$ shows good surface characteristic, without damage to the substrate. In comparison, while the line scan 
method has shown good performance at $14 \mathrm{~W}$ and $880 \mathrm{~mm} / \mathrm{sec}$ the area scan method with same parameter and $0 \%$ overlap shows unremoved top resin layer. This could be attributed to the Gaussian beam effect of the $\mathrm{CW} \mathrm{CO}$ laser beam, and it was effectively addresses with $25 \%$ beam overlap.

To further appreciate the surface characteristic of the laser irradiated CFRP samples, a laser treated surface using the systematically selected process parameters of power = $14 \mathrm{~W}$, speed $=880 \mathrm{~mm} / \mathrm{sec}$, and overlap $=25 \%$, was compared with three other surfaces that included an untreated surface, an acid etched treated surface and an abrasive treated surface in terms of their wetting angle and surface energy, which were measured using a Data Physics OCA20 micro goniometer with SCA20 control. This was achieved through the use of the Sessile Drop technique, with which $2 \mu$ l of purified water was dispensed at a constant rate of $1 \mu \mathrm{l} / \mathrm{s}$ onto each of the investigated surfaces. The contact angle for each surface was then measured using the Laplace-Young method while the total surface energy and its polar and dispersive components were calculated by means of the OwensWendt-Rabel-Kaelble geometric mean theory. For each surface, measurement of the contact angle was repeated six times with the average calculated in each case.

A plot of the resulting average contact angles for the four CFRP samples of different pretreated conditions is shown in Figure 7. The figure shows the average contact angle of the laser treated CFRP composite to be the least compared to even the two other samples that receive pre-treatment with other surface preparation techniques. What however needs to be noted from the figure is the fact that the average contact angle of the untreated sample 
is the highest, which is suggesting that surface treatment using any technique is advantageous in terms of its reduction effect on contact angle, which is favourable for adhesive bonding [16].

From the calculated values of the total surface energy and its polar and dispersive components for the four samples of pre-treated conditions, the wetting envelope [16] was constructed and the resulting graph is as shown in Figure 8. The figure shows that the area enclosed by the graph for both the abrasive treated and acid etched surfaces are prominently larger than the untreated CFRP specimen. For the laser treated surface, the wettability has dramatically risen, as highlighted by their large wetting envelopes. The graph shows that a total wetting of a commonly used adhesive for the bonding of composite structures can be achieved, as its surface energy (Hysol $9695\left(\sigma^{\mathrm{P}}=2.2 \mathrm{~mJ} / \mathrm{m}^{2}\right.$, $\left.\sigma^{\mathrm{D}}=46.0 \mathrm{~mJ} / \mathrm{m}^{2}\right)$ is located within the enclosed area for laser treated sample.

The effect of surface treatment on the bonding strength of CFRP-CFRP joints was tested by carrying out a single lap shear test. As shown in figure 9, the lap shear test was performed on $1.5 \mathrm{~mm}$ thick CFRP sample with dimensions of $51 \times 12.5 \mathrm{~mm}$. A two part epoxy resin (Evo-Stik Express Syringe - BOSTIK) was used to bond the CFRP samples together. Constant adhesive bond-line thickness of $0.7 \mathrm{~mm}$ was maintained for each of the sample, with lap shear overlap of $15 \times 12.5 \mathrm{~mm}$. The adhesives were then cured at room temperature for 12 hours, within dedicated clamping system, prior to the lap shear test. 
As can be seen from Figure 10, surface treatment resulted in significant increasing effect on the shear strength of the adhesive bond and laser surface treatment in method in particular shows marginally better performance than the conventional techniques.

\section{CONCLUSIONS}

The laser surface modification of CFRP composite using a $\mathrm{CW} \mathrm{CO}_{2}$ laser is presented in this paper. Results show that it is feasible to remove the top resin layer of the CFRP with a $\mathrm{CW} \mathrm{CO}_{2}$ laser, yielding a linear and uniform removal of resin layer without exceeding the damage threshold of the underlying fibres. Removal of resin with a laser power of $14 \mathrm{~W}$, speed of $880 \mathrm{~mm} / \mathrm{sec}$ and $25 \%$ beam overlap shows overall excellent results and high quality. The three-dimensional FEA model developed to study the heat transfer and removal characteristics revealed that with proper control of the maximum temperature, the top resin layer can be removed without damaging the substrate. These results thus suggest the resin removal mechanism to thermal based. The study also revealed that compared to an untreated sample or even abrasive treated and acid etched samples laser resin removal can significantly increase the surface energy of a CFRP sample. This observation thus reinforces the potential use of $\mathrm{CO}_{2}$ laser systems as an alternative technique for surface preparation of composites.

\section{ACKNOWLEDGEMENT}

The authors acknowledge the support offered by the UK Engineering and Physical Sciences Research Council (EPSRC) under the grant EP/L01968X/1. 


\section{REFERENCES}

1. Bachmann, M.; Avilov, V.; Gumenyuk, A.; Rethmeier, M. Numerical simulation of full-penetration laser beam welding of thick aluminium plates with inductive support. Journal of Physics D: Applied Physics 2012, 45, 035201.

2. Krishnakumar, S. Fiber Metal Laminates - The Synthesis of Metals and Composites. Materials and Manufacturing Processes 1994, 9, 295-354.

3. Elaldi, F.; Elaldi, P. Processing and Environmental Effects on Composite Repairs. Materials and Manufacturing Processes 2011, 27, 255-259.

4. Lee, S. Review of: “ADHESION AND BONDING IN COMPOSITES” edited by R. Yosomiya, K. Morimoto, A. Nakajima, Y. Ikada and T. Suzuki Marcel Dekker Inc. 270 Madison Avenue, New York, NY 10016 357pages, hardbound, 1990. Materials and Manufacturing Processes 1992, 7, 153-155.

5. Astrom, B.T. Manufacturing of polymer composites 1997: CRC Press.

6. Davis, G.D. Contamination of surfaces: origin, detection and effect on adhesion. Surface and interface analysis 1993, 20, 368-372.

7. Wingfield, J.R.J. Treatment of composite surfaces for adhesive bonding. International journal of adhesion and adhesives 1993, 13, 151-156.

8. Esfahani, R.; Coupland, J.; Marimuthu, S. Microstructure and mechanical properties of a laser welded low carbon-stainless steel joint. Journal of Materials Processing Technology 2014.

9. Burnett Jr, L.H.; Conceição, E.N.; Pelinos, J.E.; Eduardo, C.D.P. Comparative study of influence on tensile bond strength of a composite to dentin using Er: YAG laser, 
air abrasion, or air turbine for preparation of cavities. Journal of clinical laser medicine \& surgery 2001, 19, 199-202.

10. Belcher, M.A.; Wohl, C.J.; Hopkins, J.W.; Connell, J.W. Laser surface preparation for bonding of aerospace composites. Proceedings of the ICE-Engineering and Computational Mechanics 2011, 164, 133-138.

11. Ozel, M. Behavior of concrete beams reinforced with 3-D fiber reinforced plastic grids, 2002, UNIVERSITY OF WISCONSIN-MADISON.

12. Prinsloo, F.; Van Heerden, S.; Ronander, E.; Botha, L. Efficient TEA CO2-laserbased coating removal system, in XVI International Symposium on Gas Flow, Chemical Lasers, and High-Power Lasers 2006, International Society for Optics and Photonics: Austria.

13. Sato, H.; Nishio, S. Polymer laser photochemistry, ablation, reconstruction, and polymerization. Journal of Photochemistry and Photobiology C: Photochemistry Reviews 2001, 2, 139-152.

14. Negarestani, R.; Sundar, M.; Sheikh, M.; Mativenga, P.; Li, L.; Li, Z.; Chu, P.; Khin, C.; Zheng, H.; Lim, G. Numerical simulation of laser machining of carbon-fibrereinforced composites. Proceedings of the Institution of Mechanical Engineers, Part B: Journal of Engineering Manufacture 2010, 224, 1017-1027.

15. Turner, M.W.; Crouse, P.L.; Li, L.; Smith, A.J.E. Investigation into CO2 laser cleaning of titanium alloys for gas-turbine component manufacture. Applied Surface Science 2006, 252, 4798-4802. 
16. Belcher, M.; Wohl, C.; Hopkins, J.; Connell, J. Laser surface preparation and bonding of aerospace structural composites; In Proceedings of the SAMPE symposium and exhibition. Hampton, USA, 2010. 
Table 1: Material properties of the epoxy resin and carbon fibre

\begin{tabular}{|l|l|l|l|l|l|}
\hline Material & Conductivit & Density & Specific & Diffusivit & Decomposition \\
& $\mathbf{y}(\mathbf{W} / \mathbf{m K})$ & $\left(\mathbf{g} / \mathbf{c m}^{\mathbf{3}}\right)$ & Heat & $\mathbf{y}\left(\mathbf{c m}^{2} / \mathbf{s}\right)$ & Temperature \\
& & $(\mathbf{J} / \mathbf{k g K})$ & $(\mathbf{K})$ \\
\hline Epoxy resin & 0.1 & 1.21 & 1884 & 0.0004 & $673-723$ \\
\hline Carbon Fibre & 50 & 1.85 & 710 & 0.66 & $3273-3573$ \\
\hline
\end{tabular}


Table 2: Design of experiment for the line scanning operation

\begin{tabular}{|l|l|l|l|l|l|l|l|l|l|l|}
\hline Parameter & \multicolumn{1}{|l|}{ Values } \\
\hline Power (W) & 5 & 8 & 11 & 14 & 17 & 20 & 23 & 26 & 29 & 32 \\
\hline Speed (mm/sec) & \multicolumn{8}{|l|}{40 to1195 (with constant increment of $105 \mathrm{~mm} / \mathrm{sec})$} \\
\hline
\end{tabular}


Table 3: Design of experiment for the area scanning operation

\begin{tabular}{|l|l|}
\hline Parameter & Values \\
\hline Overlap (\%) & $0,25,50$ \\
\hline Power $(\mathrm{W})$ & 14 \\
\hline Speed $(\mathrm{mm} / \mathrm{sec})$ & 880 \\
\hline
\end{tabular}


Figure 1. Experimental strategy used to find the key process variables through a two-

phase operation.

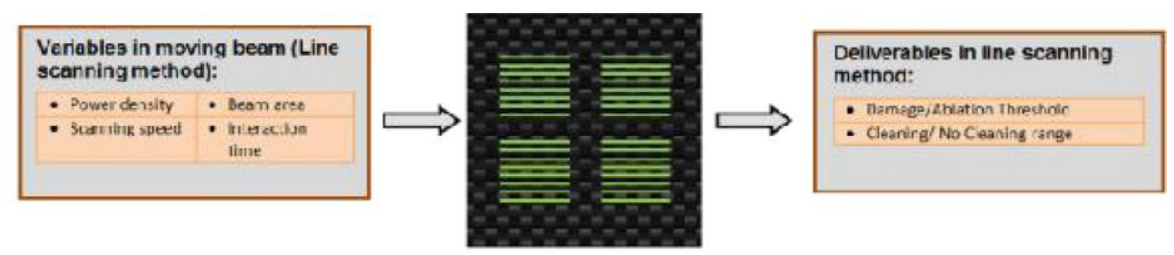

(a) Phase 1: Linear line scan technique

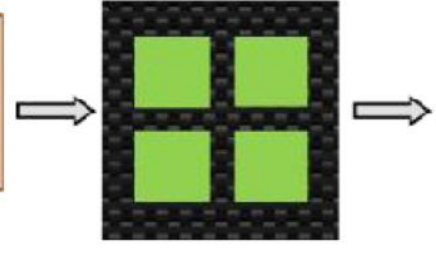

Dellveragles in Area scanning Veriables in moving
scanning method)

- Dower diansity - Raam area

- sannine speec - Uverlad

- interaction time

(b) Phase 2: Laser surface processing technique

- Domogelatletion Thresheld

- Clesning/ No Ocaning ronge 
Figure 2. Effect of laser parameters on surface conditions observed on the irradiated

\section{CFRP.}

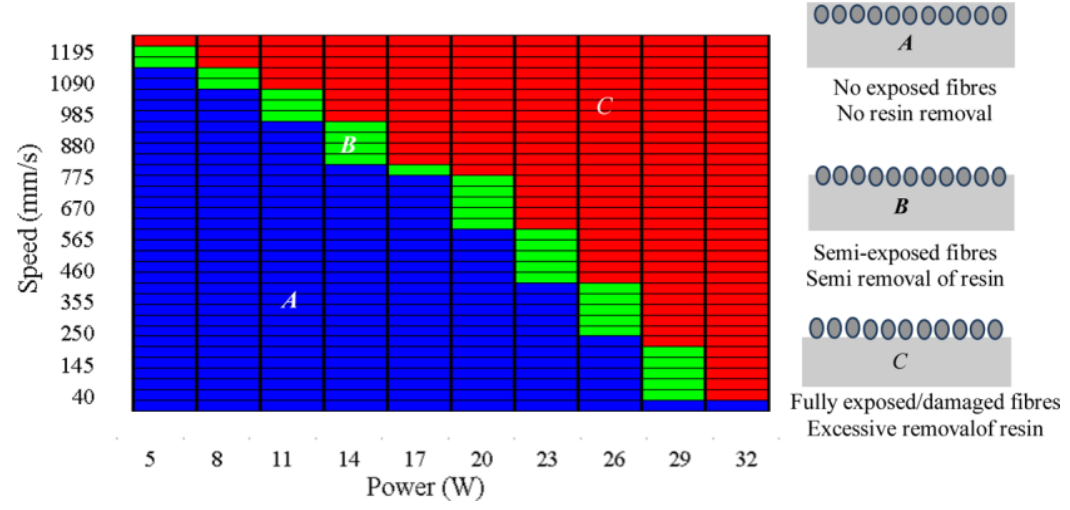


Figure 3. Optical micrographs of laser treated line at speed of $880 \mathrm{~mm} / \mathrm{sec}$ and varying powers of $8 \mathrm{~W}, 14 \mathrm{~W}$ and $20 \mathrm{~W}$, respectively.

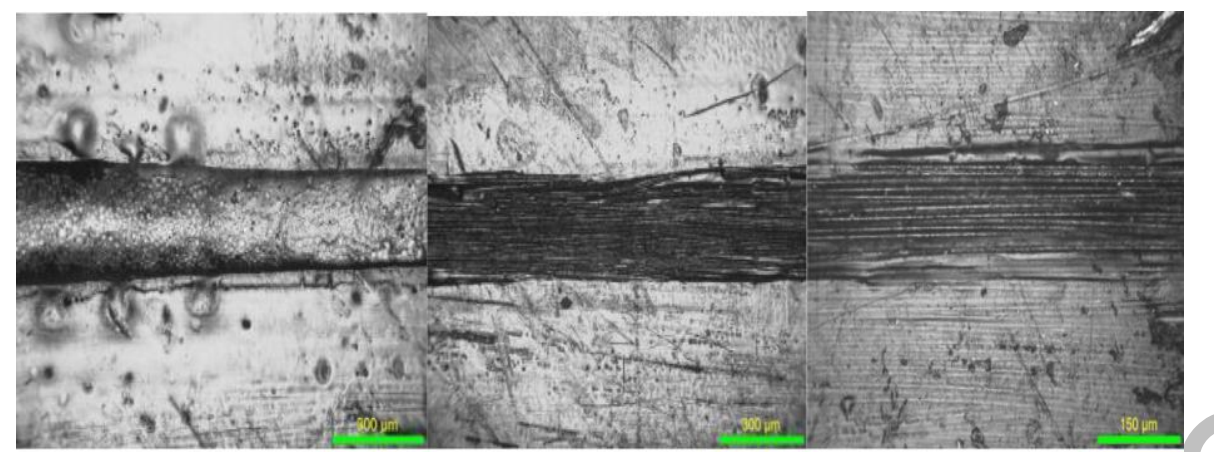
(a) power $=8 \mathrm{~W}$
(b) power $=14 \mathrm{~W}$
(c) power $=20 \mathrm{~W}$

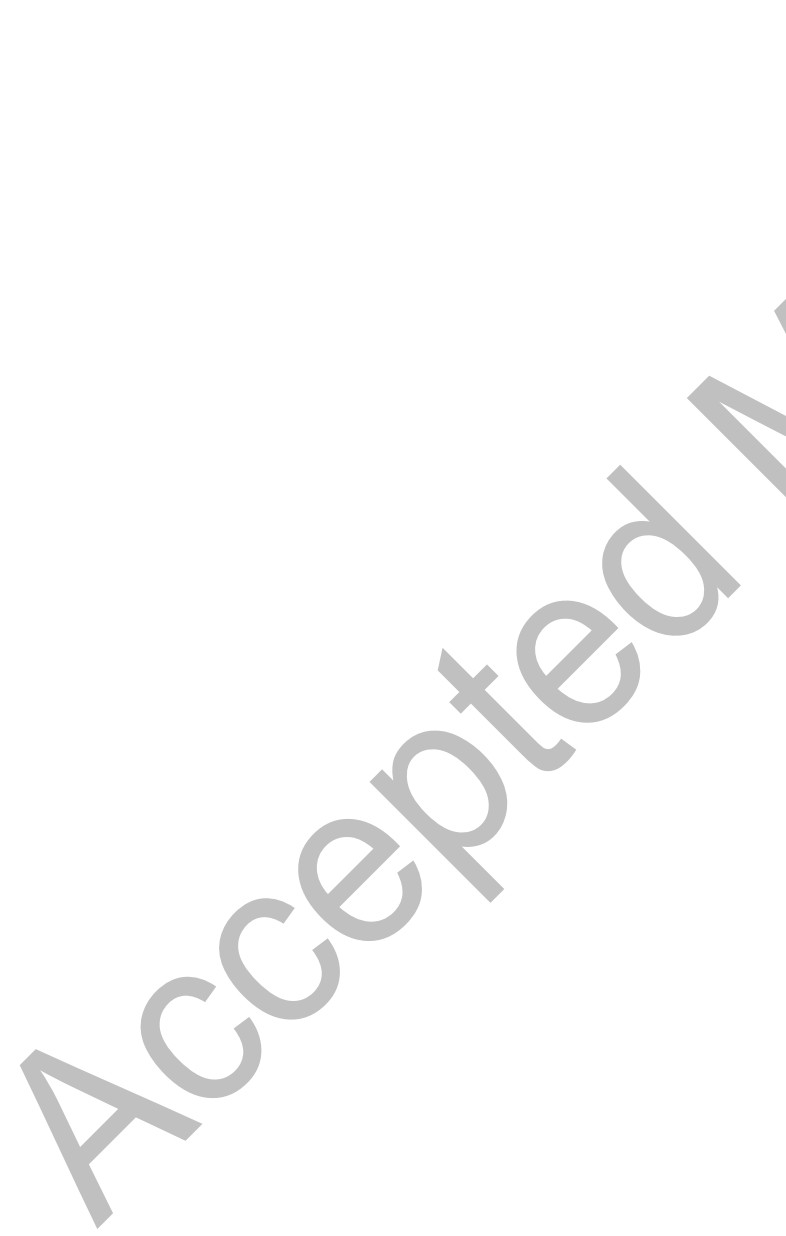


Figure 4. Effect of laser power on temperature $(\mathrm{K})$ and ablation characteristic $($ speed $=$ $880 \mathrm{~mm} / \mathrm{sec})$.

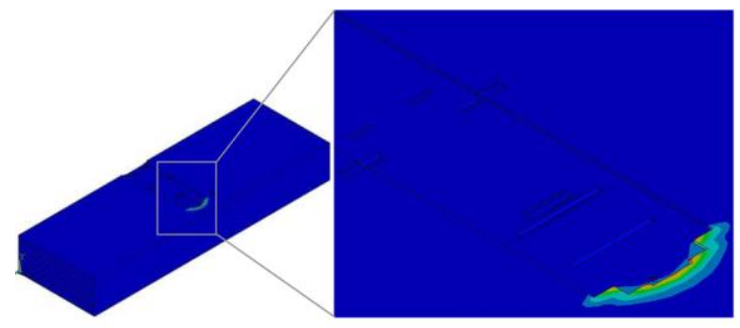

(a) Power $=8 \mathrm{~W}$

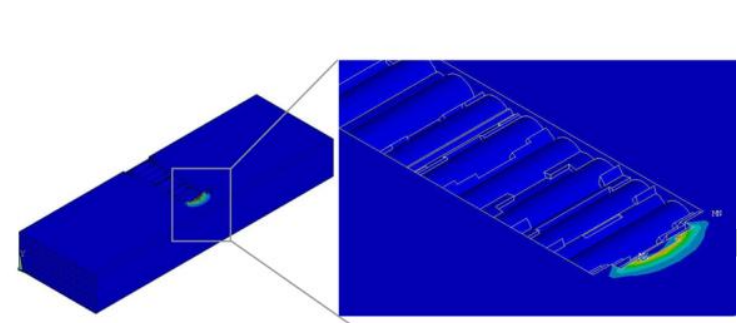

(b) Power $=14 \mathrm{~W}$

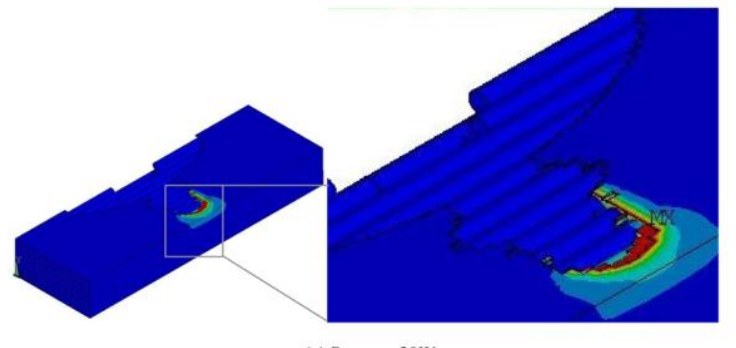

(c) Power $=20 \mathrm{~W}$ 
Figure 5. Scanning strategy of laser surface modification over an area.

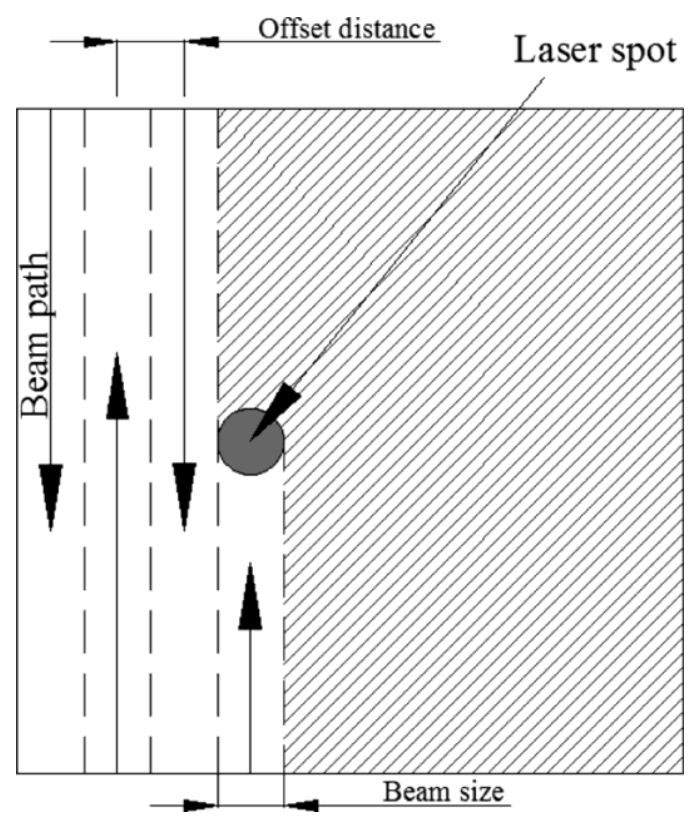


Figure 6. Optical microscopic image of laser treated area $($ power $=14 \mathrm{~W}$; speed $=$ $880 \mathrm{~mm} / \mathrm{sec})$.

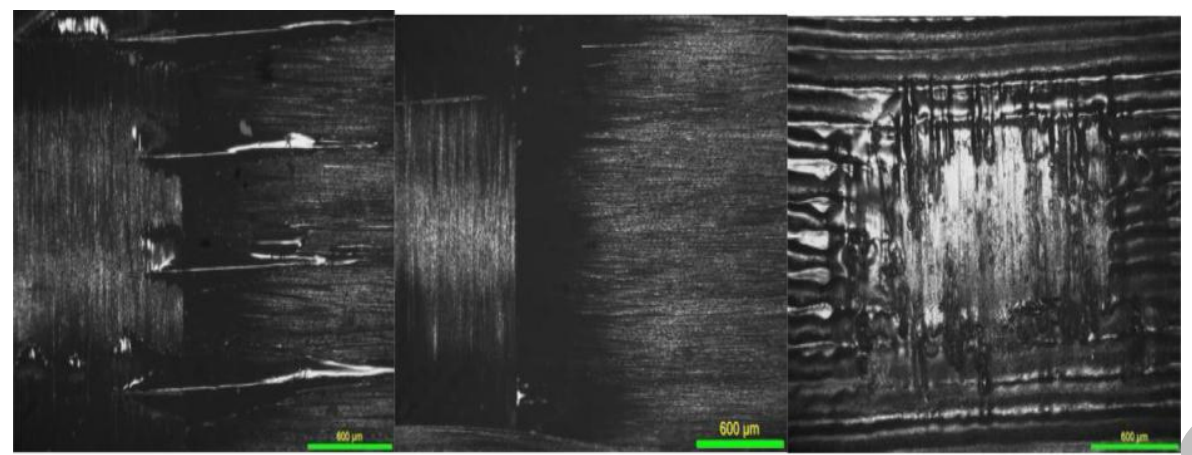

(a) Overlap $=0 \%$

(b) Overlap $=25 \%$

(c) Overlap $=50 \%$ 
Figure 7. Contact angle in CFRP with various surface processing conditions.

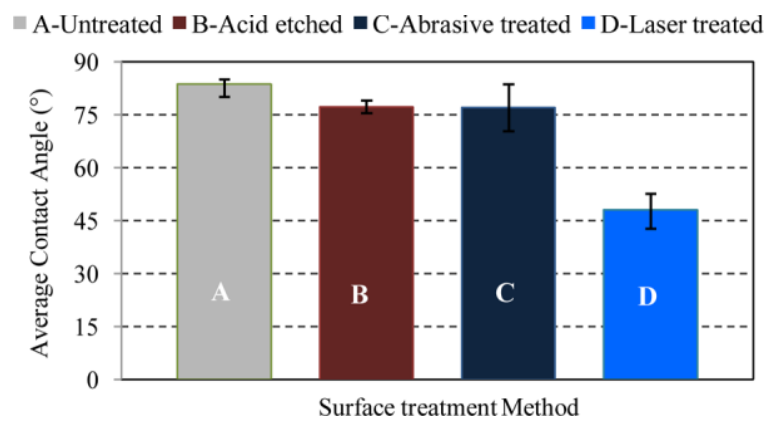


Figure 8. Graph showing the wetting envelopes for each of the pre-treated samples.

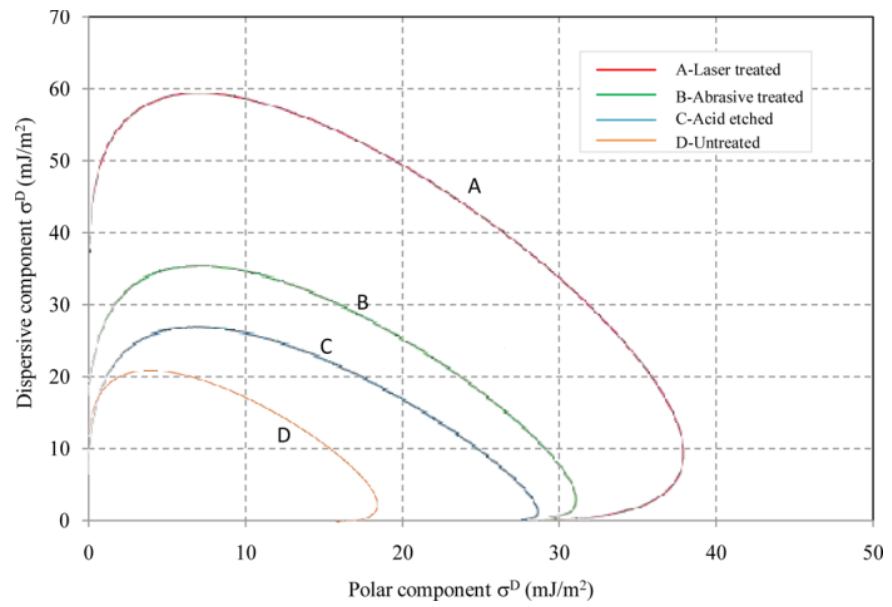


Figure 9. Schematic illustration of the joint geometry used in the lap shear test.

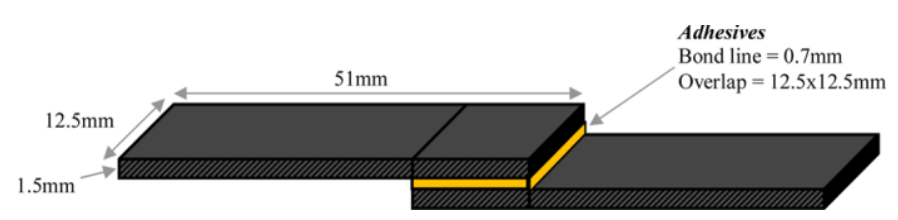


Figure 10. Effect of surface treatment method on adhesive bond shear strength.

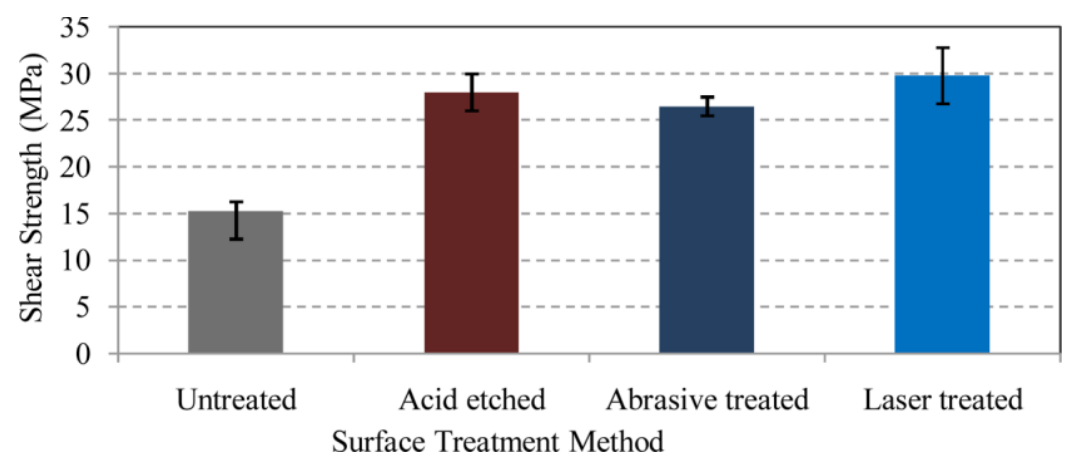

